$\Phi=\Phi$

\title{
Measuring cost of illness analysis of diarrhoeal diseases in north-western Nigeria
}

\author{
Akbar Salihu 1*, Hassan H. Suleiman ${ }^{2}$, Muhammad M. Ibrahim ${ }^{3}$ \\ ${ }^{1}$ International Committee of the Red Cross, Abuja, Nigeria \\ ${ }^{2}$ Department of Economics, Bayero University Kano, Nigeria \\ ${ }^{3}$ Department of Microbiology, University of Maiduguri, Nigeria \\ *Corresponding author E-mail: gwamaduniya@yahoo.com
}

\begin{abstract}
Background: Global estimates of morbidity due to diarrhoeal diseases stood at 1.7 billion cases per year, leading to a mortality rate of 760 000/year among children under five. These figures have considerable consequences for individuals, families and the society in the form of social disruption, lost economic opportunities and health costs.

Objectives: This study sought to measure the cost of illness analysis of diarrhoeal diseases among patients attending infectious disease hospital, Kano. It is focused on those specifically diagnosed with diarrhoeal diseases out of the general population of patients with infectious diseases.

Methods: The prevalence-based approach was used to measure the cost of managing diarrhoeal diseases from the period of September 2015 to March 2016.

Results: Utilizing primary and secondary data, it was discovered that the average amount (in Naira) needed for managing diarrhoeal disease at the center to be 5100.8 naira, direct medical cost was 917 naira, direct non-medical cost was 294.8 naira and indirect cost account for the highest at the cost of 3889 naira.

Conclusions: This study provides policy makers with valid information that could be useful in health budget planning and implementation.
\end{abstract}

Keywords: Cost of Illness, Diarrhoeal Disease; Health Budget Planning; Prevalence Approach; Nigeria.

\section{Introduction}

In most of economic and business decision making processes, private or public, the term 'cost' should always be considered while its counterpart varies from benefit (in cost-benefit analysis, CBA), to effectiveness (in cost-effectiveness analysis, CEA), and especially in healthcare fields, to quality-adjusted life years (QALYs) or latent utility (in cost-utility analysis, CUA). Though sometimes measured in different forms, costs are most commonly measured in monetary terms for a direct comparison among alternative options. Cost of illness (COI), known as burden of disease (BOD), is a definition that encompasses various aspects of the disease impact on the health outcomes in a country, specific regions, communities, and even individuals. The category of COI can range from the incidence or prevalence of disease to its effect on longevity, morbidity along with the decrease in health status and quality of life (QoL), and financial aspects including direct and indirect expenditures that result from premature death, disability or injury due to corresponding disease and/ or its comorbidities. Accurate knowledge about COI is essential and helps us formulate and prioritize health care policies and interventions and eventually allocate health care resources in accordance with budget constraints in order to achieve policy efficiency. So, it is crucially important to understand how the costs are defined, classified and measured in the COI study. In fact, estimates of the COI using various methodologies serve many purposes. Firstly, cost estimates are frequently used to argue that policies on a disease and its related diseases should be given a high priority in a policy agenda setting. The public is entitled to a quality standard against which individual COI studies can be assessed. Without such a standard, the advocates are prone to adding extra items to highlight and frequently exaggerate the COI results. Secondly, cost estimates help appropriately target specific problems and policies. It is important to know whether a specific disease of interest involves the greater medical and/or social costs.

Additionally, the improvement of cost estimates can be a good baseline measure to determine the efficacy of health policies, programs, or any types of interventions that are designed to reduce or eradicate the detrimental disease effects. Estimates of social costs can also facilitate cross-national comparisons of the disease consequences and various approaches that are available to confronting those consequences. (Changik Jo, 2014).

Tragically, diarrhoeal disease remains one of the leading killers of children around the world, responsible for the deaths of nearly 1.6 million children annually, yet is no longer considered a global health priority. Diarrhoeal disease is the most common cause of illness and the second leading cause of child death in the world. It is claiming the lives of nearly 4,000 children each day. The burden is greatest in the developing world where access to safe water, sanitation, and medical care are often limited. Adult residents of developing countries are less likely to have sporadic diarrhoea, and when it occurs, it is unlikely to be life threatening. Therefore, diarrhoeal pathogens in adults residing in developing countries have been the subject of few investigations, and very little is known about the etiologic epidemiology of pathogens other than 
epidemic Vibrio cholerae and Shigella. Sporadic endemic diarrhoea in adults, however, contributes to the loss of productivity in developing countries and increases the risk that pathogens will be passed to susceptible children or visitors. When such infections do occur, they are often treated empirically, even though very little is known about the etiologic agents in this population; and in many cases, they prompt self-medication with antibiotics, which are often available without prescription (Okeke, 1999). The problem of ignorance among people from the developing world is a factor, that leads to lack of awareness about health matters, but patronization of traditional medication is favoured, in which case they usually spend more than what is needed for management of diarrhoea the shortage of health professionals also added to the unimaginable rise in the burden of managing a diarrhoeal disease, the little world standard practiced by professionals is not usually done by local health workers, they do wrongly prescribe, over prescribe or under prescribe, all of which leads to either direct or indirect cost to the patient, couple with most members only make do with out of pocket payment (OOP) methods. If the illness strikes an adult patient, it leads to loss in productivity, indirectly affecting the economy negatively.

For children under 5 years of age in developing areas and countries, there was a median of 3.2 episodes of diarrhoea per childyear. This indicated little change from previously described incidences. Estimates of mortality revealed that 4.9 children per 1000 per year in these areas and countries died as a result of diarrhoeal illness in the first 5 years of life, a decline from the previous estimates of 13.6 and 5.6 per 1000 per year. The decrease was most pronounced in children aged under 1 year. Despite improving trends in mortality rates, diarrhoea accounted for a median of $21 \%$ of all deaths of children aged under 5 years in these areas and countries, being responsible for 2.5 million deaths per year. There has not been a concurrent decrease in morbidity rates attributable to diarrhoea. As population growth is focused in the poorest areas, the total morbidity component of the disease burden is greater than previously. (Kosek et al., 2003). The aim of this study is to measure the cost of illness analysis on diarrhoeal disease among patients attending clinics at infectious disease hospital, Kano State of Nigeria. This study will help policy makers in the estimation of the burden of diarrhoeal disease and have a guide towards policy formulation and administration for better service delivery and improvement in the health sector.

\section{Materials and methods}

\subsection{Study area}

Kano State is situated in a semi-arid region located between latitudes $10.30^{\circ} \mathrm{N}$ to $13^{\circ} \mathrm{N}$ and longitude $7.40^{\circ} \mathrm{E}$ and $10.39^{\circ} \mathrm{E}$. The state is noted for its fairly stable climate with relatively minor changes in temperature and humidity. It has a population of 10,013,224 (NPC, 2006), with an almost equal distribution of male $(51 \%)$ and female (49\%). Urban drift from rural areas within Kano, other states in Nigeria as well as North and West Africa, has provided a steady stream of migrants adding to Kano's growing population. The state has somewhere between one secondary health facility to 120,000 and 200,000 population per hospital Malaria, diarrhoeal diseases, measles and other vaccine preventable diseases, acute respiratory diseases and malnutrition remain leading causes of morbidity and mortality especially among children in the State. Poverty is high in Kano State with $61 \%$ of the population living below the poverty line. Life expectancy is 51 years for males and 52.2 years for women. Only $37.6 \%$ of the population had access to running water (KSEEDS, 2005).

\subsection{Study population}

The target population includes all patients diagnosed with diarrhoeal diseases attending the various unit/wards of the Infectious Disease Hospital (IDH), Kano State during the period of the study.
The hospital is a 150 bed facility consisting of chest ward, general ward, diarrhoea treatment center, tetanus ward, TB/MDR ward and pediatrics ward. The hospital has a staff strength comprising thirteen medical doctors, two pharmacist, two laboratory scientist, fifty three nurses, twenty one pharmacists, sixteen laboratory technicians, two radiographers, six X-ray technicians, twenty four primary health care workers, twelve security men, twenty three sub staffs, three messengers, four medical record officers, five maintenance officers and a single ambulance driver. The hospital also provides comprehensive testing, treatment and care for HIV/AIDS under the support of USAID/PEPFAR implemented by FHI 360. The FHI 360 provides staff training and support, procurement of test-kits and drugs, logistics support and chain management strengthening.

\subsection{Study design}

Economic analysis, specifically cost of illness analysis (COI) will be used to carry out this study. The prevalence-based approach will be considered to measure the cost of diarrhoeal disease treatment in infectious disease hospital (IDH) within the specified time period.

\subsection{Sample size estimation}

The sample size was determined using the formula

$$
\mathrm{n}=\mathrm{Z}^{2} \mathrm{pq} / \mathrm{d}^{2}
$$

Where

$\mathrm{n}=$ minimum sample size desired

$\mathrm{Z}_{1-\alpha / 2}=$ standard normal deviation at $95 \%$ confidence levels $=1.96$

$\mathrm{P}=$ estimated proportion of variable of interest in the population (proportion of diagnosed diarrhoeal disease clients) $=87.6 \%$ $\mathrm{p}=0.876$

$\mathrm{q}=$ complementary probability of estimated proportion of variable of interest in the population (proportion of diagnosed diarrhoeal disease clients $)=1-\mathrm{P}=1-0.876=0.124$

$\mathrm{d}=$ level of precision $=5 \%=0.05$ i.e. we would like the result to be within $5 \%$ of the true value

$$
\mathrm{N}=1.96^{2} \times(1-0.876) / 0.052=191
$$

To compensate for non-response and poorly completed questionnaires, the desired sample size, 'NF' was multiplied by a factor $(100 / 100-\mathrm{R} \%)$ to increase the sample size so that the precision of the study shall not be jeopardized; $\mathrm{R} \%$ is the percentage loss to non-response by participants or poorly filled questionnaire by the interviewer; assumed to be $10 \%$.

To compensate for non-response of $10 \%$, we used

$$
\text { (NF x 1/1-R \%), }
$$

Where $\mathrm{NF}=$ calculated sample size

$\mathrm{R} \%=$ Non-response rate

Therefore, $\mathrm{N}=191 \times 1 / 1-0.1=211.7 \approx 212$.

So 250 questionnaires where used.

\subsection{Sampling technique for study participants}

Systematic random sampling technique was used and sampling interval was generated using the formula:

Where:

$$
\mathrm{K}=\mathrm{N} / \mathrm{n}
$$

$\mathrm{K}=$ Sampling interval

$\mathrm{N}=$ Total number of diagnosed diarrhoeal disease clients $=\sim 1000$

It was used as the Sampling frame

$\mathrm{n}=$ Calculated sample size $=250$

Therefore, $\mathrm{K}=4$. A client is considered as a sampling unit Numbers were allocated to each participant within the sampling frame (proportion of diagnosed diarrhoeal disease clients). First participant was selected from the first four clients in the register using simple random sampling through blotting. Then the rest of 
the participants were selected as every subsequent fourth client till the desired sample size (250) was obtained.

\subsection{Average percentage cost}

The summation of the average percentage cost is the real average cost of the variable where a member can belong to more than one group. The average percentage cost is calculated by multiplying the average cost by the percentage it represent and then dividing by hundred.

Average percentage cost $=(\% \mathrm{x}$ average cost $) / 100$

Real average cost $=\sum$ average percentage cost.

\subsection{Sources of data collection}

Two major sources of data collection were used in the study primary and secondary sources of data. In using primary sources, the study depends on personal observation and questionnaire administration. The secondary sources are textbooks, journal articles, newspapers, unpublished thesis and internet based materials.

\subsection{Questionnaire development}

The Questionnaire was constructed in a simple language and consists of both open and closed ended questions. It is subdivided into four sections (A-D). The first section (section A) sought information's about the socio-demographic variables (Bio data) Name was excluded from the Bio data for confidentiality. Section B of the questionnaire was designed to assess the direct cost of diarrhoeal disease from the respondents. Section $\mathrm{C}$, of the questionnaire was designed to assess the direct non-medical cost of diarrhoeal disease from the respondents. Section $\mathrm{D}$, is a section on the indirect cost of diarrhoeal disease from the respondents.

\subsection{Data analysis}

The date collected were analyzed using Microsoft excel spread sheet. Descriptive statistical methods like frequency distribution tables and simple percentage were used.

\subsection{Limitations of the study}

Some respondent were skeptical about the interview especially among the completely illiterate and the females. A long time had to be taken to explain to them the purpose of the interview before they accepted. This was solved by using the nurses and other female health workers to enlighten the respondents on significance of the research. Time constraint is another factor. The period for the study is so short to enable for a larger sample size

\section{Results}

Out of the 250 respondents tested, $62.0 \%$ were females while $38.0 \%$ were males. Based on occupation, greater percentage of the respondents was found to be House wives (40\%) and the least were Students $(7 \%)$. Most of the respondents fall within the age group of 26-40years $(44.8 \%)$, and the least were respondents in the age category of $<10$ years with $2.4 \% .69 .6 \%$ of the respondents are married, $12 \%$ widowed, $8.8 \%$ divorced and $8.8 \%$ were single (Table 1).

Majority had primary school education only with $30.8 \%$ while the least among them had tertiary education $(4.8 \%)$. Majority of the respondents have a daily income of \#1000-\#5000 (71.6\%), and he least were found to have a daily income of >\#15000 (0.4\%) (Table 2).

Analysis of the Direct Medical Cost showed that all the respondents had consulted with a medical professional where $32 \%$ saw a medical doctor, $27 \%$ consulted with other health workers, $21.1 \%$ had self-medication and $19.3 \%$ consulted a traditional doctor. Cost of consultation was free. About $62 \%$ obtained a card and it was free with no charges. $34.8 \%$ did some laboratory investigations. $22.2 \%$ did EUCr (Electrolyte, Urea and Creatinine) at an average cost of about \#500, which is the most expensive of the tests. The least expensive were Malaria Parasitology and Stool Microscopy which were conducted at an average cost of \#100 and a percentage cost of $9.9 \%$ and $3.2 \%$ respectively. For all the above investigations, it applies that any person diagnosed with diarrhoea at infectious disease hospital Kano will be charged \#156.6 as obtained from the total average percentage cost. All the respondents had taken a medication due to the diarrhoeal illness. $28.1 \%$ took ORS at an average cost of \#100, 11.8\% had Flagyl at an average cost of $\# 1$, I.V fluid $(10.6 \%)$ at cost of \#200, I.V ceftriaxone $(10.1 \%)$ at an average cost of \#500, I.V flagyl (9.7\%) at an average cost of $\# 100$ and I.V promethazine $(8.8 \%)$ at an average cost of \#30 each. Those that took other drugs out of the available options are about $20.9 \%$, at average cost of \#100. The total average percentage cost of drugs was \#760.4. 37.6\% where admitted into the hospital because of this illness but the hospital stay was free (Table 3).

Analysis of the Direct Non-Medical cost revealed that $86.8 \%$ of respondents had to use a means of transportation with the majority (39.6\%) using tricycle (Adaidaita Sahu) at an average cost of \#150, the least was found to be those that used their personal car $(6.5 \%)$, at an average cost of \#300. Thus, the average percentage cost of coming for treatment at IDH is \#294.8.

Table 1: Distribution of Socio-Demographic Characteristics of Respondents Attending Infectious Disease Hospital Kano

\begin{tabular}{|c|c|c|}
\hline Demographic Parameter & Frequency & Percentage $(\%)$ \\
\hline \multicolumn{3}{|l|}{ Sex } \\
\hline Male & 95 & 38.0 \\
\hline Female & 155 & 62.0 \\
\hline \multicolumn{3}{|l|}{ Age } \\
\hline$<10$ & 6 & 2.4 \\
\hline $10-25$ & 81 & 32.4 \\
\hline $26-40$ & 112 & 44.8 \\
\hline $41-55$ & 22 & 8.8 \\
\hline$>55$ & 29 & 11.6 \\
\hline \multicolumn{3}{|l|}{ Marital Status } \\
\hline Single & 22 & 8.8 \\
\hline Married & 174 & 69.6 \\
\hline Divorced & 22 & 8.8 \\
\hline Widow & 32 & 12.8 \\
\hline \multicolumn{3}{|l|}{ Occupation } \\
\hline Farmer & 24 & 9.0 \\
\hline Civil Servant & 37 & 15.0 \\
\hline Traders & 72 & 29.0 \\
\hline Students & 17 & 7.0 \\
\hline Housewives & 100 & 40.0 \\
\hline
\end{tabular}

$\mathrm{N}=250$ 
Table 2: Literacy Level and Daily Income of Respondents Attending Infectious Disease Hospital Kano

\begin{tabular}{lll}
\hline Demographic Parameter & Frequency & Percentage $(\%)$ \\
\hline Level of Education & 77 & 30.8 \\
Primary & 43 & 17.2 \\
Secondary & 12 & 4.8 \\
Tertiary & 60 & 24.0 \\
Qur'anic & 58 & 23.2 \\
None & & 16.8 \\
Daily Income & 42 & 71.6 \\
$<1000$ & 179 & 9.6 \\
$1000-5000$ & 24 & 1.6 \\
$5001-10000$ & 4 & 0.4 \\
$10001-15000$ & 1 & \\
\hline 15000 & & \\
\hline
\end{tabular}

Table 3: Direct Medical Cost of Diarrhoeal Disease among Respondents Attending Infectious Disease Hospital Kano

\begin{tabular}{|c|c|c|c|}
\hline Variable & Frequency $(\%)$ & Average Cost (Naira) & Percentage Cost (\%) \\
\hline \multicolumn{4}{|l|}{ Direct Medical Cost } \\
\hline Medical consultation & $250(100)$ & 0.00 & 0.00 \\
\hline - Medical Doctor & $88(32.6)$ & 0.00 & 0.00 \\
\hline - $\quad$ Traditional Medics & $52(19.3)$ & 0.00 & 0.00 \\
\hline - $\quad$ Self-Medication & $57(21.1)$ & 0.00 & 0.00 \\
\hline Card Purchase & $155(62)$ & 0.00 & 0.00 \\
\hline Laboratory Investigation & $87(34.8)$ & - & - \\
\hline - $\quad$ Stool Microscopy & $12(3.2)$ & 100 & 3.2 \\
\hline - Electrolyte/Urea/Creatinine & $83(22.2)$ & 500 & 111.0 \\
\hline - $\quad$ Malaria Parasitology & $37(9.9)$ & 100 & 9.9 \\
\hline - Widal Test & $37(9.9)$ & 150 & 14.9 \\
\hline - $\quad$ Stool M/C/S & $6(1.6)$ & 400 & 6.4 \\
\hline - Others & $21(5.6)$ & 200 & 11.2 \\
\hline - $\quad$ None & $178(47.6)$ & 0.00 & 0.00 \\
\hline Hospital Admission & $94(37.6)$ & 0.00 & 0.00 \\
\hline Tabs Flagyl & $98(11.8)$ & 1 & 3.5 \\
\hline ORS & $234(28.1)$ & 100 & 28.1 \\
\hline I.V Ceftriaxone & $84(10.1)$ & 500 & 202 \\
\hline I.V Flagyl & $81(9.7)$ & 100 & 58.2 \\
\hline I.V Promethazine & $73(8.8)$ & 30 & 5.2 \\
\hline I.V Fluid & $88(10.6)$ & 200 & 254.4 \\
\hline Others & $174(20.9)$ & 100 & 209.0 \\
\hline
\end{tabular}

$\mathrm{N}=250$

Table 4: Direct Non-Medical Cost and Indirect Cost of Diarrhoeal Disease among Respondents Attending Infectious Disease Hospital Kano

\begin{tabular}{|c|c|c|c|}
\hline Variable & Frequency $(\%)$ & Average Cost (Naira) & Percentage Cost $(\%)$ \\
\hline \multicolumn{4}{|l|}{ Direct Non-Medical Cost } \\
\hline Cost of Transportation: & $217(86.8)$ & - & - \\
\hline - Car & $14(6.5)$ & 300 & 19.5 \\
\hline - $\quad$ Tricycle (Adaidaita) & $86(39.6)$ & 150 & 178.2 \\
\hline - Taxi & $38(17.5)$ & 100 & 17.5 \\
\hline - $\quad$ Motorcycle (Babur) & $23(10.6)$ & 70 & 7.4 \\
\hline \multicolumn{4}{|l|}{ Indirect Cost } \\
\hline Sick Leave Due to Illness & $134(53.6)$ & - & - \\
\hline - $\quad$ Medically Certified Absence from Work & $58(45.2)$ & 4Days (6000) & 2712 \\
\hline - $\quad$ Reduced Hours of Work for Gradual Reintegration & $76(54.80)$ & $3 \mathrm{hrs}(250)$ & 137 \\
\hline Accept Help due to illness & $238(95.2)$ & - & - \\
\hline - Friends, Relatives, Acquaintances & $236(99.2)$ & $12 \mathrm{hrs}(1000)$ & 992 \\
\hline - $\quad$ Professional Aid Bodies (e.g. Red Cross) & $2(0.8)$ & $12 \mathrm{hrs}(6000)$ & 48.0 \\
\hline
\end{tabular}

Indirect Cost of diarrhoeal disease among respondents showed that $53.6 \%$ of them had been on a sick leave due to their illness. Out of which $45.2 \%$ where certified absent from work for an average of four days at an average cost of about \#6000 and $54.8 \%$ had reduced hours of work for gradual reintegration of three hours costing averagely \#250. So the total percentage cost from loss of hours of work added up to \#2849. 95.2\% of the respondents had received help from others and out of this, $99.2 \%$ received help from friends and relatives for an average of 12 hours at an average cost of \#1000. $0.8 \%$ had help from professional bodies such as Red Cross costing averagely \#6000. Total average cost of help from others is \#1040 (Table 4).
The cost of illness is defined as the Direct Medical Cost (DMC) + Direct Non-Medical Cost (DNC) + Indirect Cost (IC) cumulatively.

But Direct medical cost $(\mathrm{DMC})=$ Consultation Fee + Cost of Card + Cost of Investigation + Cost of Medication + Cost of Admission/Hospital Stay

$$
\mathrm{DMC}=0+0+156.6+760.4+0
$$

$$
\mathrm{DMC}=\# 917
$$

Direct Non-Medical Cost $(\mathrm{DNC})=$ Cost of Transportation.

$$
\mathrm{DNC}=\# 294.8
$$


Indirect Cost (IC) $=$ Cost due to Loss of Productivity $=$ Cost from Loss of Hours of Work + Average Cost of Help from Others

$$
\text { IC }=2849+1040 \text {. Therefore, } \mathrm{IC}=\# 3889
$$

Therefore Cost of Illness (COI) of diarrhoeal disease from Infectious Disease Hospital Kano is calculated as follows;

$$
\begin{gathered}
\mathrm{COI}=\mathrm{DMC}+\mathrm{DNC}+\mathrm{IC} \\
\mathrm{COI}=917+294.8+3889=\# 5,100.8 .
\end{gathered}
$$

\section{Discussions and recommendation}

Health expenditure in Nigeria has not been rising as a percentage of the nation's gross domestic product (GDP). Still the proportion of GDP spent on total health care remained relatively constant (less than the WHO recommendation) over the past thirty years. Even though private health insurance and government programs cover a little portion of drug expenditures, a sizeable amount of drug cost is paid directly by consumers. The cost of illness COI becomes a major concern to patients, government and third party. Cost of illness studies are important pharmaco-economic evaluations of new therapies. By evaluating the humanistic impact of disease and the resources used in treating a condition, it becomes easier for the government, the third party and even the patient to have an overview in making decisions. Presently in Kano, the state government in directly involved in helping the people with medical health bills in terms of consultation fee, card fee, hospital stay fee and some basic drugs charges. This had drastically reduced the cost of illness encountered by patients in seeking for medical services. From the above study, we can see that majority of the respondents fall within the age range of 26-40year having $44.8 \%$, and the least were children <10years. This is due to the presence of an alternative Paediatric Hospital close by that attends to child illnesses. Majority of the respondents are house wives $40 \%$, this could be partly by the fact that most men in Kano tend to be negligent or careless about their health conditions and are at higher risk of self-medication. Majority of the respondents live on daily income ranging between 1001-5000 making $71.6 \%$, this could be because house wives also fall within this range as their daily income comprise of an average of two jobs, a house maid and that of a nanny ( and based on the federal government minimum wage of $18000,(18,000 * 2=36,000 /$ month $)$. The direct medical cost of treating diarrhoea at IDH Kano is about nine hundred and seventeen naira (\#917), that of direct non-medical cost sums up to two hundred and ninety four naira eight Kobo (\#294.8k) and that of indirect cost is about three thousand eight hundred and eighty nine naira (\#3889). It can be seen that most of the cost are due to indirect cost which makes the person less productive and indirectly affecting the economy in a negative way. Contrary findings were reported by Pegram et al., (1998), shows that direct medical cost account for the highest cost due to diarrhoeal illness. This can be attributed to differences in healthcare management and the level of income of the population for the study. Cumulatively it can be seen that the total cost of illness from diarrhoeal diseases cost an average of five thousand one hundred naira and eight kobo (\#5100.8)

This study showed how much could be spent in the management of diarrhoeal diseases from the time of presentation to discharge. Help from the government has drastically reduced the cost, but if the disease could be promptly prevented, there will be good economic growth and development of the nation because the money will be spent on developmental projects instead of the management of diarrhoeal disease. Sanitation should be encouraged among the population to reduce the risk for developing diarrhoeal disease. This is a preventive strategy in fighting against diarrhoea since it is mostly associated with poor environmental sanitation. The level of education from the respondents is not encouraging as most are just at the primary school level, this means the literacy level is poor, and so government should try and build more schools and enlighten the people about the importance of education. Some of the essential drugs used for treating diarrhoea are still sold, for that reason some might be having the illness but cannot come for medical help and end up with self-medication or traditional concoction. So there should be free essential drugs across the hospitals such as ORS, tabs Zinc, tabs Flagyl, caps Doxycycline and IVF. Community development and enlightenment is very essential. Government should try as much as they could through community medicine.

\section{Acknowledgement}

We acknowledge with thanks, the management of the Infectious Disease Hospital, Kano and the Diarrhoea Treatment Center for giving us the permission to conduct this study.

\section{References}

[1] Changik Jo (2014) Cost of Illness Studies: Concepts, Scopes and Methods, Clin Mol Hepatol. 20(4), 327-337 https://doi.org/10.3350/cmh.2014.20.4.327.

[2] Kano State Economic Empowerment and Development Strategy. (2005). Kano State Government Bullettin. 14-15

[3] Kosek M, Bern C, Guerrant RL (2003). The global burden of diarrhoeal disease, as estimated from studies published between 1992 and 2000. Bull World Health Organ. 81, 197-204.

[4] Okeke I. N., A. Lamikaura and R. Edelman (1999). Socioeconomic and behavioral factors leading to acquired bacterial resistance to antibiotics in developing countries. Emerging Infectious Disease. 5, 18-27 https://doi.org/10.3201/eid0501.990103.

[5] National Population Commission (2006). National and State Population and Housing Tables, Census Priority Tables. Vol 1.

[6] Pegram G. C., Rollins N, and Espey Q (1998). Estimating the costs of diarrhoea and epidemic dysentery in KwaZulu-Natal and South Africa. Water SA 24(1), 11-20. 